\title{
Between Vladivostok and Africa: Teaching European Studies in Australia.
}

\author{
BEN WELLINGS ${ }^{1}$ \\ Australian National University \\ ben.wellings@anu.edu.au
}

\begin{abstract}
Learning about Europe in Australia at the higher education level requires lecturers and tutors to ground their teaching in students' pre-existing understanding of Australia's links with Europe. This link needs to be made to students in the classroom and to university management as a case for embedding European Studies within university administrative structures. I will also argue that whilst students display a keen interest in contemporary Europe, European Studies itself is best seen as a sub-or cross-discipline, particularly of politics, history and international relations underpinned by the study of languages and it is here that Europe' has much to teach Australian university students.
\end{abstract}

\section{Introduction}

The first time I taught about Europe was in Australia. I had been in Australia for a bit over two years and for the majority of this time I had been researching for my $\mathrm{PhD}$ at the Australian National University. Having just returned from a three month field trip to Europe, I was excited at the prospect of tutoring a foundational course on European history. In preparing for my first tutorial I hit upon what I thought was a brilliant idea: I would start off a discussion about the idea of Europe by discussing whether or not Russia was part of it or not! Thus enthused, I asked the students in my first tutorial to consider whether they thought Vladivostok was in Europe. I waited for a lively discussion about Europe and its culture, geography, history and politics to ensue... and waited... and waited. Finally, one of the students had the courage to ask the right question: 'Where's Vladivostok?'

The reason that this was the right question to ask was because I had assumed knowledge on behalf of the students that wasn't there. Worse than this, in so doing, I risked stifling the students' interest in Europe, which clearly was there. So this is the basic point which I want to make in this article: that

\footnotetext{
${ }^{1}$ Dr Ben Wellings is Convenor of European Studies, College of Arts and Social Sciences, at the
} Australian National University, Canberra, Australia. 
teaching European Studies in Australia in the tertiary sector requires lecturers and tutors to ground their teaching in students' pre-existing understandings of Australia's relations with Europe. The observations made in this article are drawn from my seven years teaching about Europe in the School of Social Sciences - as a tutor and lecturer - and as Deputy-Director of the National Europe Centre at the Australian National University in Canberra. Many of the observations will be impressionistic and anecdotal or will be based on comments made by students in post-course evaluations. Accordingly, this article has three sections: the first on the experience if teaching European Studies in lectures and tutorials; the second on course design in light of that experience and the third on the place of European Studies within university administrative structures. What follows then is probably what Susan Toohey would call a 'curriculum ideology'. ${ }^{2}$ It would be unwise to try and provide any generalities about teaching styles - each teacher has their own style and it is not for me to teach people more experienced than I how to do their jobs. In this sense I do not offer any prescriptive advice (although on a personal note, I am pleased that I finally have a captive audience so that I can tell my joke), merely views and opinions which I hope - unlike my use of Vladivostok - will provoke a lively and useful debate.

\section{On the Stage}

One point to make at the outset is that by and large the level of knowledge about Europe amongst students beginning their studies at the ANU is really quite low. One student enthused to me at the end of a first year course on modern European history how pleased she was that she now knew so much about Europe - previously she had been aware that it was above Africa, but that was about it! This was an extreme example, but it did reinforce for me that the enthusiasm to learn about something novel and somewhere new is there, but that it needed to be supported with the familiar. Going back to my first tutorial, it was interesting to reflect on why I had chosen Vladivostok to initiate debate. I had toyed with the idea of starting off with the question 'Is Britain part of Europe?' but had rejected this as too hackneyed. But, of course, it wasn't hackneyed for the students, who had heard of the debate and were able to comment on it and participate more readily. What worked even better was when I grounded the question even further in the students' own knowledge and experience and asked 'Is Australia part of Europe?' This question allowed the students to use their own understandings of Australia's relationship to Europe to help form an understanding of what Europe is and why it is like that, as well as allowing me as the tutor a glimpse of the assumptions that the students were bringing to the discussion. I have been opening my courses with this discussion for some years now and the discussion itself usually boils down to Australia being culturally similar to, but geographically distinct from, Europe. It was interesting to note that at the very outset of their tertiary education, students were treating concepts as givens. There was little understanding of what 'culture' was and is let alone how it is produced. Furthermore, Europe itself was ascribed a uniformity in

\footnotetext{
${ }^{2}$ S. Toohey, Designing Courses for Higher Education. Buckingham: The Society for Research into Higher Education \& the Open University Press, 1999, p. 44.
} 
contrast with Australia, which was usually described as 'diverse' and 'multicultural'. Comparative work of this sort of this sort need not always be so explicit, although making direct contrasts can at times be very helpful, particularly at the outset of teaching about Europe.

However, whilst this level of knowledge is not exactly Rousseau's tabula rasa, it does provide some opportunities to teach about Europe without some of the ingrained assumptions and prejudices that one might find when teaching in Europe itself. For instance, even within universities, let alone amongst the wider public, the discussions concerning the European Union can too easily become bogged down into a 'are you for Europe or against it' debate. Each side employs caricatures of the other when seeking to win over students and the public to its cause: pro-Europeans linking the EU with Progress and the Enlightenment, portraying it as a bulwark against the darker side of human nature; anti-Europeans casting the EU as an erosion of individual liberty and hard-won national sovereignty. Fortunately in Australia, few people outside of the farming community care much about the EU, and since it can be perceived neither as a the Ultimate Triumph of Prussian Militarism nor the Way Forward for Humanity, debate can proceed in a more rational manner.

But one of the downsides of this advantage is that having distanced oneself from all the drama and passion in debates about contemporary Europe, the subject matter risks become dull and remote from Australian students' lives and experiences. I too have experienced some of this distance when reading Pat Barker's Regeneration trilogy whilst relaxing on a beech in Queensland or drinking a glass of wine al fresco on a warm summer's evening whilst reading about the memory of the Holocaust in post-War Europe. So in this regard, we might assume that - initially at least - contemporary debates about the past in Europe might seem remote to an eighteen or nineteen year old Australian. An analogy that I have used before is that in such a context teaching about, say, the European Union risks becoming like a day-old English ale - dull, flat and unpalatable. The challenge is to make it more like a refreshing Czech pilsner quaffed at the end of a hot summer's day - something that you would really look forward too. To carry the analogy even further and ground it in the Australian experience, teaching about the EU may be akin to drinking Cooper's Pale Ale - the subject matter may seem opaque at first, but the overall effect at the end is one of satisfaction. Aside from this digression into styles of beer, the need to inject some excitement into my undergraduate teaching raised two related questions. The first concerned the scope of the term 'European Studies' and the second concerned what was distinctive about European studies in Australia. These questions feed directly into teaching strategies in the tutorial room and the lecture theatre, but necessarily impact on course design.

\section{Behind the Scenes}

Evidently, the term European Studies encompasses far more than the teaching of the European Union alone, although when it comes to the question of distinctiveness I think that the EU has something to offer here. European and 
EU Studies are obviously related, and yet are quite distinct and European Studies should not be treated as a synonym for EU Studies. They should however, be able to reinforce each other. I am tending more and more to a situation whereby I teach a course on the European Union, but one which is supported by course on post-War European history - which helps explain why the EU came into existence in the first place - and the politics of a member state (in my case the United Kingdom) which can help illustrate the ways in which the EU impacts on member-states. This allows students to explore the distinct nature of the EU whilst grounding their understanding in the recent past and the politics of a particular member state, in my case one with which many students have some familiarity with.

Anecdotally, it seems to me that the majority of first year students arriving at the ANU with an interest in international relations, politics, history and languages have visited Europe already. ${ }^{3}$ Given this first-hand experience of the sub-continent, students' interests are initially operating at a broad level of history and society, possibly as a corollary of an interest in languages, but just as likely a curiosity about the world outside of Australia and an interest in travel as a sort of transitional rite of passage into the status limbo of studenthood. Such experiences can be drawn into discussions about Europe allowing students to relate their own experiences to the subjects under discussion. For example, some earlier work I did with the National Museum of Australia, revealed that most young Australians who have visited Gallipoli have done so as a side trip from London, where they lived in expatriate communities by-and-large confined to Acton and Shepherd's Bush and used budget airlines to explore other parts of Europe. Often their tour to Gallipoli took in other places of historical interest such as Troy and Istanbul. Many visitors to Gallipoli reported a heightened sense of being Australian as a result, and a sense of identification which they brought back to Australia with them after their travels were done. So not unlike the soldiers who left Australia during the Great War, many young Australians have had their conscious sense of Australian identity formed within a European context. The practical outcome of this for my teaching is that I have begun to place discussions about the formation of nation-states in nineteenth century Europe just after ANZAC Day in order to link in discussions with things such as the invention of tradition' (still provoking good tutorial discussions to this day) and relate it to deeply-felt Australian experiences.

Another exercise which proved useful in harnessing students' experience of travel came when teaching about the European Union. In order to try and convey some of the sense in which the European Union is made up of a diversity of large, small and medium-sized member states, each with their own political issues relating to the EU, I opted for the principal of devolution. Each tutorial group was assigned a member state of the EU about which they had to find information, such as population size, length of time in the EU and attitudes towards the European integration. Then representatives from each tutorial gave a short presentation on that member state at the start of the

\footnotetext{
${ }^{3}$ I would be interested to see if this were the case in other universities given that many ANU students are drawn from Canberra and whose families have stable and relatively high levels of income compared with other regional cities.
} 
lectures. This also allowed students a greater degree of involvement in lectures. Both these examples are illustrative of a teaching technique which aims to relate students' own experience to the study of contemporary Europe.

But there is also the issue of distinctiveness. In appealing to students I try and ask myself why any Australian should want to study Europe as opposed to say Asia, the Pacific or the Americas? One response is that much of European history has provided the foundations for contemporary Australian culture and society. Another response is that Europe's history has helped to create a novel political experiment and one which is seen as a model of regional integration. A third response is that European Studies is clearly well set up to provide a language component in a student's overall education, and although there may be a sense of complacency in the Anglophone world about the necessity of learning foreign languages when most of the world seems to speak English, as educators I think we should encourage our charges to embrace the opportunities brought about by acquiring another language as much as possible. ${ }^{4}$

Continuing on the theme of distinctiveness, there might also be a way - and this is completely impressionistic - that European Studies at the ANU benefitted from the presidency of George W Bush. The (sometimes overstated) tension between Europe and America during the first eight years of this decade was a topic of considerable interest to students in my classes. Europe's multilateralism contrasted starkly, and often favourably, to the Bush administration's shifting alliances. It seemed to me that Australia's involvement in these alliances and wars prompted students to ask themselves what alternatives might be available and Europe's 'actually existing multilateralism' seemed to appeal on this score.

There was another, less explicit way in which America was present in much of my teaching about Europe and that was through the textbooks available to accompany large, introductory courses on European history. As Norman Davies has pointed out, and indeed tried to correct, this market is dominated by textbooks designed to cater for courses offered in US universities on 'Western Civilization'.5 Distinguishing 'European history' from that of 'Western Civilization' is a tricky one for educators and is not helped by the dominance of 'Western Civ' texts catering for this large and lucrative US market. Reflecting on this issue ten years ago, Gary Ianziti noted that 'Western Civ' 'gradually became the Americanized version of European history'. ${ }^{6}$ This situation came about once this version of history had been conscripted into the Cold War struggle between 'Western' civilization and 'Eastern' Communism and clearly Australia could be fitted nicely into this 'Western' historical narrative, although at some disservice to geography. Ianziti also argues for the teaching of European history ab initio and with a

\footnotetext{
${ }^{4}$ My five-year-old son pointed out on a recent visit to Europe that English was the national language of Australia, England, Scotland, America and hotels.

${ }^{5}$ N. Davies, Europe. East and West. London: J onathan Cape, 2005, p. 46.

6 G. Ianziti. 'Beyond "Western Civ". Teaching the histories of the new Europe' in

A. Pavkovic and C. Welch with C. O'Brien (eds.), Teaching European Studies in Australia: problems and prospects. Papers from the first CESAA workshop on teaching European Studies. Melbourne:

Contemporary European Studies Association of Australia, 1999, p. 40.
} 
geographical depth that can match its temporal one. I agree with the latter notion, but I think there is a case for locating much of the study of Europe in the contemporary and modern eras. But as Ianziti points out, to focus solely on the recent past 'goes against the grain of the European project as a whole'. ${ }^{7}$ This seems to me to be a good reason to leave that entire sweep of European history well alone. I worry that aligning the teaching of Europeans Studies too closely with the 'European project' will only lead to a kind of legitimizing narrative of contemporary European integration which we need not concern ourselves overly in Australia and makes 'European Studies' serve a similar ideological purpose to 'Western Civ' or national histories of the nineteenth and twentieth centuries. Furthermore, I have never been too convinced that the aspects of ancient European civilization that are commonly claimed for Europe or the West - notably Hellenic culture or the Roman Empire - are strictly European or Western. Clearly myths like that of Europa are of Hellenic origin and the importance of Latin on contemporary European Romance languages is evident. Yet both these civilizations were significantly oriented around the Mediterranean and Asia Minor as much as within the sub-continent that people understand as Europe today, so we must be wary of making them too 'European' after the event.

Of course the terms 'contemporary' and 'modern' are relative, but I have found that a broad understanding of Europe's past from the sixteenth century (that is to say since the beginnings of Europe's trans-Atlantic expansions and the Reformation), followed by a focus on post-War history, politics and society, works for me. Again, these decisions are guided by the need to locate this teaching about Europe within the Australian experience of the students. Thus Europe's overseas expansion helps students understand the settlement of Australia; discussions about the Reformation ultimately help some students understand why their parents sent them to Catholic schools and Anglican students to realize that their religion is a form of Protestantism too. The list could go on through the development of science, the impact of Enlightenment ideas on contemporary political thought, the development of the state system, European dominance and decline - and finally post-War renewal.

Thus teaching about Europe is absolutely fundamental to an understanding of present-day Australia. But the exchange need not be all one way. I have had some preliminary discussions with a publisher who was interested in a textbook which could cover European history to be sold in the Australian market and one which might present a distinctively Australian perspective on this history. Since the question of what exactly is distinctive about an Englishspeaking off-shoot of a European nation has bedeviled Australian nationalists for about two centuries, I have no easy answers to this question. However, it seems to me that a distinctive Australian perspective might consist of a sensitivity to the impact and continuing ramifications of colonialism, in both its social and environmental guises; a greater awareness of Europe's impact in Asia and the Pacific (without losing sight of the importance of European expansion in the Americas and Africa); and a distance from debates about both European integration in Europe and Western Civ in the US that seemed

\footnotetext{
${ }^{7}$ Ibid., p. 38.
} 
to have generated some of the 'muscular liberalism' of some of the American textbooks.

Such teaching strategies are aimed at large first year teaching. Thereafter, courses on contemporary Europe are better served by textbooks and individual course designers can bring their own interests much more to bear through set chapters and articles. However, we all know that teaching can be most effective when some sort of meaningful relationship can be established between the tutor and the student. This means a careful balancing act between maintaining high enrolment figures for European Studies courses and being able to devote attention to the interest of individual students in these subjects. A further difficulty can then arise that if one devotes time to encouraging students and ensuring that they receive a high quality education, time for research - what we are all ultimately judged on - can just fly out of the window. This is perhaps where initiatives such as Learning Communities and Summer Schools can allow those students who are really motivated by studying Europe to give free reign to their interests which like-minded peers. I have had some great success with Learning Communities, for example. Learning Communities are an idea that developed out of the US university system, but have been adapted to local needs at the ANU. In the US system, these Communities are based in the halls of residence, where it is usual for all students to spend some time living in university accommodation. In Australia, where many students spend most of their years at university living with their parents (!), Learning Communities can serve different functions. They can enable students, for whom university is often akin to 'Year 13' of school but with further to commute, to spend more time on campus. They can also bridge a gap between formal learning in the classroom and learning outside of the university and in the community. Fortunately in Canberra, the community here comprises of many European embassies and the EC Delegation, who have given their time and energy to supporting the students who organise and run something called the Contemporary Europe Learning Community (CELC). CELC has a programme of activities that run throughout the year and which culminate in an annual dinner symposium on a topic regarding contemporary Europe.

Summer Schools such as those run by the National Europe Centre, attracting students from around the other Centres in Australia and New Zealand as well as from Asia, are another way of providing focused education on Europe as well as cohering a group of students interested in the study of Europe. Again, support from academic staff in non-teaching periods, visiting fellows and European diplomats have been helpful in turning such Summer School into to something distinctive for students. Establishing exchanges in Europe for credit (as Monash University and the New Zealand European Union Centres Network have already done) is another way of creating a distinctive education that we can offer prospective students who are looking for practical applications for the academic interests. Maintaining undergraduate numbers is evidently important, but distinctiveness is doubly important when attracting fee paying Masters students in a competitive educational marketplace. 


\section{In the Gods}

However, it is not only students that we need to impress in order to make European Studies in Australia viable and sustainable. I have tried to apply insights gained from teaching and course design when attempting to position of European Studies within wider university structures to sustain our broadchurch subject for the long term. Again the issue of distinctiveness arises, but this time it is about making a case for the usefulness of European studies within the university and at the same time making claims for its distinctiveness so that it does not get subsumed into other disciplines or disappears altogether.

My first response to this dilemma has been to consolidate the Contemporary Europe major across several disciplines within the ANU's School of Social Sciences so that teaching about Europe supports the teaching of other disciplines, notably international relations, politics and history. This marks a change from the original location of many staff members teaching European studies in language departments. ${ }^{8}$ However, my own impressions (and those of student recruitment officers at the ANU) that interest in European Studies is growing, must be offset with the reality of significant structural changes to individual universities (most notably at the University of Melbourne) and the case that can be made for retaining and growing what appears to be a niche specialization such as European Studies. In one sense, one of the problems with European Studies is the breadth of disciplines which such a catholic heading can encompass. A quick glance at the course offerings in the ANU's Contemporary Europe major for 2009 revealed that students taking this major could elect courses from History, Philosophy, Sociology, Politics, Film Studies, Italian, German, English as well as French, Drama, Linguistics, Art History and all this in addition to European Studies courses too. Whilst this multi-disciplinarity is, in my view, essential for an undergraduate education, my concern is that European Studies can seem to university management too much like a degree or major thrown together from any courses that make passing reference to Europe and thus lacking coherence and a core constituency. Therefore, in order to provide effective teaching to as large a number of interested students as possible, I have tried to ground the teaching of European Studies at the ANU across what I think of as the core disciplines of European Studies in Australia: history, politics and international relations, supported by the acquisition of one or more European languages.

I have selected these three areas out of my experience of teaching European Studies at the ANU since 2001. It seems to me that these disciplines best reflect students' interest in Europe and responding to these will help sustain and grow European Studies in Australia. This approach brings us back to grounding the study of Europe in the students' pre-existing knowledge of Europe. I conduct a straw poll each year at the beginning of my course called

\footnotetext{
${ }^{8}$ E. Rechniewski, They All Speak English Anyway: integrating languages into the European Studies curriculum' in A. Pavkovic and C. Welch with C. O’Brien (eds.), Teaching European Studies in Australia: problems and prospects. Papers from the first CESAA workshop on teaching European Studies. Melbourne: Contemporary European Studies Association of Australia, 1999.
} 
Europe in the Modern Era: the foundations of international relations, which introduces students to key concepts in IR through the study of European history from Europe's overseas expansion to the beginning of the Great War. This course usually attracts around 350 students (although 'attracts' might be the wrong word since it is compulsory for students doing the ANU's IR degree some of whom don't initially understand why the past has anything to do with international relations). Of these, when asked how many of them have been to Europe, usually around 70 per cent respond in the affirmative, meaning that much of the interest they generate at the outset of the course is linked to overseas travel. It is for this reason that history - European history - is seen as a distinctive area of interest to many students.

So this is one area in which teachers and course designers of European Studies in Australia can harness interest. A quick look at the travel brochures in STA Travel, for example, reveals that Europe is sold to young people as being rich in history. Although most brochures aimed at people in their twenties feature photos of people in their twenties on the front covers, old stuff like castles, cathedrals, ruins and even antiquated lampposts are often visible in the background. Of course, being rich in history is a mixed blessing, especially for those people forced to live through those times that now generate such student interest. So it is not just the material remains of the past itself which is of interest to Australian students, but debates about the past which can help shed light on contemporary Australia. For example, if I had a dollar for every time a taxi driver or student said to me that 'Australia has no history', I'd be writing this article on a champagne-laden yacht moored off Fiji (I'm not; I'm at home drinking a cup of tea). What struck me about this insistence, especially when I first arrived in Australia in 1998, was that history seemed to me to be hotly debated here and very much in the public domain. These debates about history were, of course, a response to things such as the Wilson Report on the Stolen Generations, but a grounding in certain aspects of European history - the reasons for overseas expansion; the hopes and fears relating to colonial schemes; ideas about race and eugenics; and ideas about human dignity - could all contribute to students' participation as citizens to debates about the legacy of the past in Australia.

Whilst history may be an important entry way to students' interest in Europe, the main growth area for student enrolments in the last nine years has been in the field of International Relations (IR). The course mentioned above Europe in the Modern Era - was created in 2002 by my predecessor as Convenor of European Studies in conjunction with IR colleagues to introduce first year IR students to key concepts such as state, nation and imperialism via modern European history, as well as counting towards History and Contemporary Europe majors. This course was based upon but replaced the course I had first tutored, called the Foundations of European Civilisation. Situating this course within International Relations had a dramatic effect on enrolments. In 2001, the Foundations of European Civilisation was a component of the Contemporary Europe major in the European Studies degree alone. In this guise it attracted about thirty students, mostly complementing their language studies with the Contemporary Europe major. Once this course was re-worked as part of the IR degree, enrolments began exceeding three hundred. Similarly, a course offered on the European Union 
experienced a jump from around fifty to over one hundred and seventy enrolments once it was linked to IR and Politics, rather than just Contemporary Europe alone. Thus politics is another area in which European Studies can be profitably located. And in the realm of politics - as with IR - I think that teaching about Europe can offer something distinctive; that is to say the European Union as an object of curiosity to students interested in novel and developing forms of governance.

Lastly, but by no means least, is the role of languages within European Studies. Having recently spent time in Europe and seen the employment advantages that continental Europeans have over their Anglophone colleagues, European Studies must continue its close link with the acquisition of another language. Often students may come to European Studies as a corollary of their interest in acquiring a European language or through their existing knowledge of a heritage language' spoken or at least comprehended at home. And this is an advantage of multiculturalism in Australia that we should encourage and profit from.

All these are strategies are designed to embed European Studies in existing university structures. Depending on which university we work for, each of us will have our own dilemmas to solve or crosses to bear in such strategies, but this type of embedding seems to make good sense. It might also be easier to pursue such a strategy in smaller universities than in larger ones, where staff teaching European Studies may have a disproportionate impact within smaller departments. But what struck me as a significant difference when reading CESAA'a last publication on teaching European Studies in Australia, produced in 1999, was the impact of European Commission funded centres in Australia and New Zealand. As universities encourage academics to search for more 'non-traditional' sources of funding, such centres (and the money that comes with them) seem like a good idea. However, this source of funding will not continue ad infinitum and efforts need to be made (and are being made) to ensure that a diversity of income streams, not least the types of fee-paying masters courses mentioned above, are developed in order to make these centres sustainable within university structures. The funding of such centres is obviously a blessing to universities looking for non-traditional sources of revenue and for those of us teaching about and researching Europe. But the potential for research across the centres will be to a large degree conditioned by pressures, time constraints and initiatives generated within the universities. The National Europe Centre's Summer School has become a good example of collaboration between the Centres that are currently in existence. However, the fate of the Contemporary Europe Research Centre at the University of Melbourne is instructive and reminds us of how low down in the scale of priorities European Studies can seem when major restructures are taking place and the time and energy which can be expended making sure that the Centres continue before meaningful collaboration can occur. Even at the ANU, the Chancelry's desire to reform the Institute of Advanced Studies (where the National Europe Centre is currently located) and its attempts to deepen its links with universities in the International Alliance of Research Universities, mean that efforts will have to be expended in these directions and possibly at the expense of greater Centre collaboration. This being said, I think the will to collaborate is there, but - in the European way - probably 
needs a distinct project around which to coalesce. In this regard, some form of teaching collaboration could be just the thing - and wouldn't M. Monnet be proud of this approach?

\section{Conclusions}

I refer back to the student above, who eventually broadened her understanding of Europe beyond some sort of land mass situated above Africa. I have not dwelt upon the background of students in Australia, many of whom are now drawn from overseas. In this case, this particular student's parents were from China and had found their way to Australia via Vietnam when she was about twelve. Thus while her lack of knowledge about Europe may be surprising, it is also quite understandable. But with her interest in languages she was able to write a very good essay on the decline of Latin as a European lingua franca. I think this speaks to the need to ground our teaching of Europe in what we can know about the student's own experiences and relate 'Europe' to these. And course design and situating European Studies within existing of novel university structures relate closely to each other, but it seems to make sense to me to locate European Studies across several disciplines so that our teaching helps, and is supported by, politics, international relations and history, whilst encouraging students to develop or deepen their knowledge of a foreign language. So if interest in European Studies can be harnessed early on by enthusiastic teaching, and deepened later by focused activities inside and outside of the classroom, I think the future for European Studies in Australia and New Zealand is bright. Change can bring uncertainty, but it can also bring opportunity, which is why good teaching about Europe needs to be pursued on two broad fronts: in the classroom and within the university. We know that Europe lies somewhere between Vladivostok and Africa: it is our job - and our pleasure - to fill in that blank part of the map. 